\title{
A NUTRITION CLINIC IN A PUBLIC SCHOOL*
}

\author{
WILLIAM R. P. EMERSON, M.D. \\ BOSTON
}

Nutrition clinics conducted for a period of time in hospital work have shown that malnourished children recover health and strength almost in direct proportion to their home control. Where there is complete control of the patients during the whole twenty-four-hour period, as in a child-helping institution, recoveries may occur in nearly 100 per cent. of all cases.

The fact that malnutrition is due only in a minor degree to poverty, to inheritance, to tuberculosis, to syphilis or to other obscure diseases, but in the great majority of cases is due to adequate causes such as physical defects, improper food habits, overfatigue and errors of home and school life, makes the work of correcting malnutrition, though partly medical, for the greater part educational. Therefore, theoretically at least, such work should be carried on in the school, where health habits and practical hygiene can be taught as a part of the school program. Accordingly, an invitation from the Bureau of Educational Experiments of New York to conduct a nutrition clinic under its auspices in a public school in that city was welcomed as an opportunity to demonstrate whether it is practical during a school régime to secure a sufficient part of the essentials of health to obtain satisfactory results. These essentials for the health of the growing child are the removal of physical defects interfering with nutrition, inducing the child to take sufficient food at frequent intervals, obtaining good air day and night, preventing fatigue, and securing sufficient home control to insure good food and health habits.

Through the cooperation of the principal, permission was obtained to conduct the experiment in Public School 64, situated in the crowded East Side. The number of children in the school was about 3,000, more than 90 per cent. of whom were Hebrews. The work was carried on under circumstances that would have been almost prohibitive were it not for the enthusiastic support of the principal, Mr. Louis Marks, and his assistants. The treatment by the Class Method was conducted in one small room, the only available space, shared by the eye clinic, the school nurses, and workers who were making a

\footnotetext{
* The following personnel assisted in the work of the nutrition clinic, February to June, 1918: Medical work: Adolphus DeSanctis, M.D., Henry J. Schreiber, M.D. Nutrition work: Miss Mabel Skilton. Tables compiled by David Mitchell, Ph.D.
} 
special survey. The children were scattered throughout the various rooms, as it was not practical to segregate the malnutrition group during the experiment nor relieve them from the pressure incident to their grade work necessary for promotion. Further difficulties existed in the fact that it was war year, one physician being obliged to leave the clinic just as the work was getting under way. Hospitals were so short of physicians that the work of removing physical defects, as diseased adenoids and tonsils, was much delayed and in large part undone. In this school building there was neither gymnasium nor hall where the floor could be used for rest periods. However, this need was met by the kind cooperation of Miss C. I. McColl of the Christodoro House nearby, who not only provided a room for rest periods, but also accommodation for the serving of lunches. The value of the experiment was greatly increased by the cooperation of the New York School Lunch Committee, which provided school lunches to various groups in order to test the effect of these lunches on nutrition.

The work was carried on locally by one physician who made first examinations and was present to help conduct the class exercises. The preparation for the class work was made by a social service worker and an assistant. Supervision of the entire work was obtained by weekly visits of the writer to the clinics and by a trained nutrition worker who spent a portion of her time at the clinics.

The conduct of the clinic was as follows:

Weighing and Measuring. - Eight hundred ninety-four children from various grades were weighed and measured without shoes, but with indoor clothing, and their percentage of underweight or overweight reckoned according to the average weights for heights computed by Boas and Burke.

The child who is chronically 7 per cent. underweight for his height is retarded practically one year in both weight and height. Such stunted children are not only undernourished, but malnourished. The weighing and measuring was for the purpose of identifying this group. Table 1 shows the number found to be of normal weight and the number 7 per cent. or more overweight or underweight for their height.

It will be seen from Table 1 that an average of 18 per cent. were underweight. Based on these figures, in New York City alone, with approximately one million school children, one hundred eighty thousand are probably malnourished. It is to be noticed that the percentage in the various groups showed no marked variation except in the groups marked "special" and "open-air." These specials include sixty-nine children examined by a psychologist and rated as excep- 
tionally bright. As a rule, they came from families living in more comfortable circumstances than the other children. Their higher rate of malnutrition agrees with our experience, that malnutrition exists to a greater degree among the rich than among the poor. The openair group consisted of twenty-five children who had found their way to the only open-air room in the building because of tuberculous history or because they were "anemic." It is interesting to note that the percentage of underweight of the specials was practically the same as that of the open-air group, which latter group was supposed to represent the twenty-five children from ten grades who most needed special care.

Table 1.-Percentagie of Overweight and Underweight Children

\begin{tabular}{|c|c|c|c|c|c|c|c|}
\hline & Grade I & Grade $V$ & Grade VI & Grade VII & Oren-air & Specials & Total \\
\hline \multicolumn{8}{|l|}{$\begin{array}{l}\text { Children i\% or more } \\
\text { overweight: }\end{array}$} \\
\hline Nianber............ & דיד & 21 & 40 & 38 & 1 & 7 & 134 \\
\hline Per cent. .......... & $10.6 \mathrm{i}$ & 16.5 & 16.3 & 22.0 & 4.0 & 10.1 & 15.0 \\
\hline \multicolumn{8}{|l|}{$\begin{array}{l}\text { From } i \% \text { overweight } \\
\text { to } 7 \% \text { underweight: }\end{array}$} \\
\hline Number.............. & $18 . \overline{1}$ & 7 & 166 & 110 & 17 & 43 & 600 \\
\hline $\begin{array}{l}\text { Per cent } \ldots \ldots \ldots \ldots \\
\text { (children to or inore }\end{array}$ & 72.5 & 62.2 & 67.8 & 63.6 & 68.0 & 62.4 & 67.0 \\
\hline \multicolumn{8}{|l|}{$\begin{array}{l}\text { ("hildren } 7 \% \text { or more } \\
\text { underweiglt: : }\end{array}$} \\
\hline Number........... & 43 & $2 \overline{7}$ & 39 & 25 & 7 & 19 & 160 \\
\hline Per cent. & 16.9 & 21.3 & 15.9 & 14.4 & 28.0 & 27.5 & 18.0 \\
\hline Tot: & 25 & 127 & 245 & 173 & 25 & 69 & 894 \\
\hline & 100.0 & ] 00.0 & 100.0 & 100.0 & 100.0 & 100.0 & 160.0 \\
\hline
\end{tabular}

Physical Examination.-The next step was a complete physical examination. This was made without clothing and according to a regular form ${ }^{1}$ in order to save time and insure no omissions. At the end of the examination all physical defects were noted under "diagnosis" in order that steps might be taken promptly for their correction. The average number of clefects found was five, the most important of which was nasopharyngeal obstruction.

Treatment.-The children were given varying treatment in six groups for the purpose of comparing results.

Class Method: The child was weighed each week and his weight charted, his diet list for two days was kept and reckoned, and the child was placed in the class according to his gain or loss. Then the various probable reasons for gain or loss as they appeared in the most evident cases were discussed with the group, and suggestions made to help in the child's gain the following week. These suggestions had to do with the use of tea or coffee, food habits, the need of open windows. the avoidance of late hours and of overtire, and of such other causes

1. Emerson, William R. P.: Standardized Physical Examinations, Arch. Pediat., July, 1918. 
as clearly prevented gain. Occasion was taken to encourage those who gained weight, and to make plain the cause in the case of those who lost weight. As each child saw his own chart and recognized the reason for gain or loss, his cooperation was obtained in every instance.

Rest Periods: A half hour was taken in the forenoon, lying on the floor wrapper in a blanket, and a similar one advised to be taken in the afternoon at home.

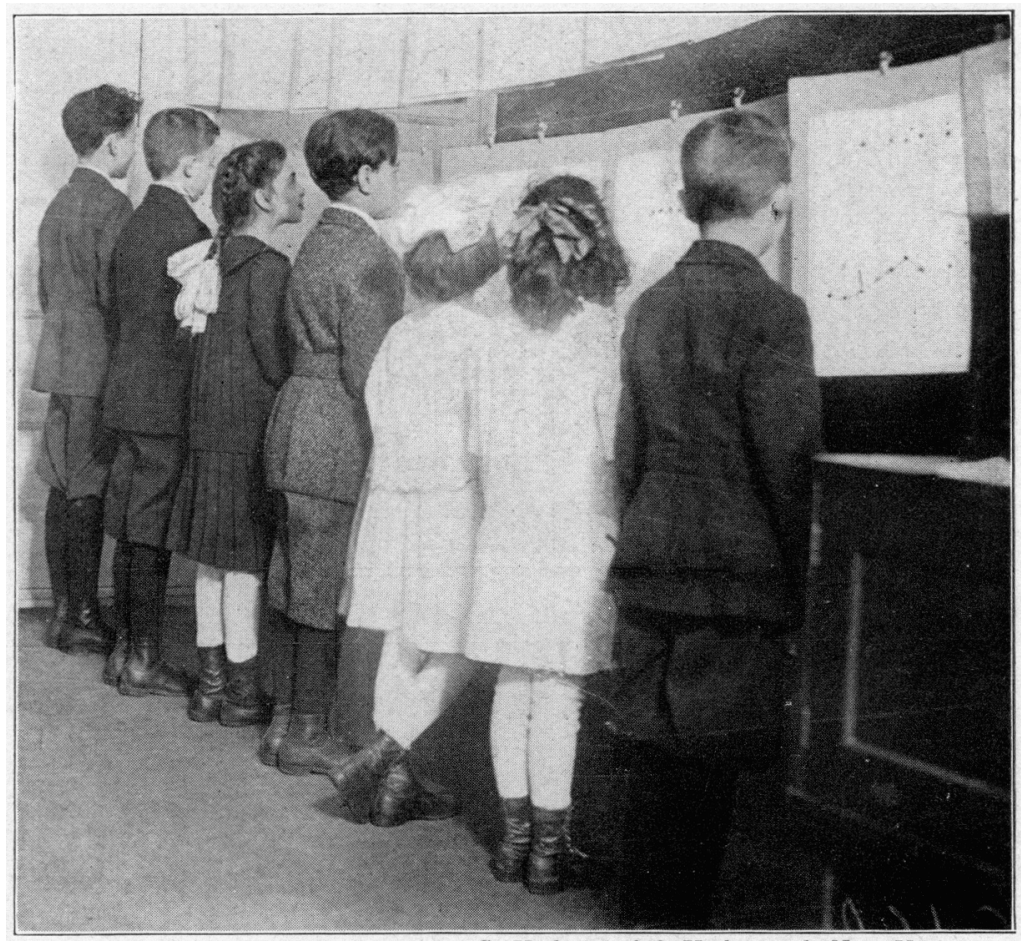

C. Inderwood \& Inderwood, New York.

Fig. 1.-On the day of the mutrition class exercise, the children are eager to examine the charts to compare their gains. Their interest to know the canse of a luss or gain is remarkable-an icleal situation for effective instruction.

Diet Records: Each week the older children were asked to bring a two-day list ${ }^{2}$ of all food taken. These lists were checked up on the day of the weighing and suggestions mate to correct any serious fault of diet and also to encourage the use of cereals and milk. Otherwise interference with the home table was avoided so far as possible.

Lunches: I small lunch, from 250 to 300 calories, was supplied to certain grotups in the midforenoon, and also a dinner of about 1.200 calories was provided to certain groups in the middle of the day.

2. Emerson. William R. P.: Record Book for Measured Feeding. 
Home Visits: Each child's home was visited by the nutrition worker with the definite object of knowing the parents, of obtaining their cooperation in the work of getting their children to gain and of finding causes in the child's home life that prevented gain. Special attention was paid to the need of open windows at night and of taking sufficient time at meals.

The six groups were treated as follows:

Grade I.-Class Method; advised to take rest period and lunch.

Grade V.-Midday dinner only.

Grade VI.-Class Method; diet records; rest; lunch; midday dinner.

Grade VII.-Class Method: diet records; rest; lunch; no midday dinner.

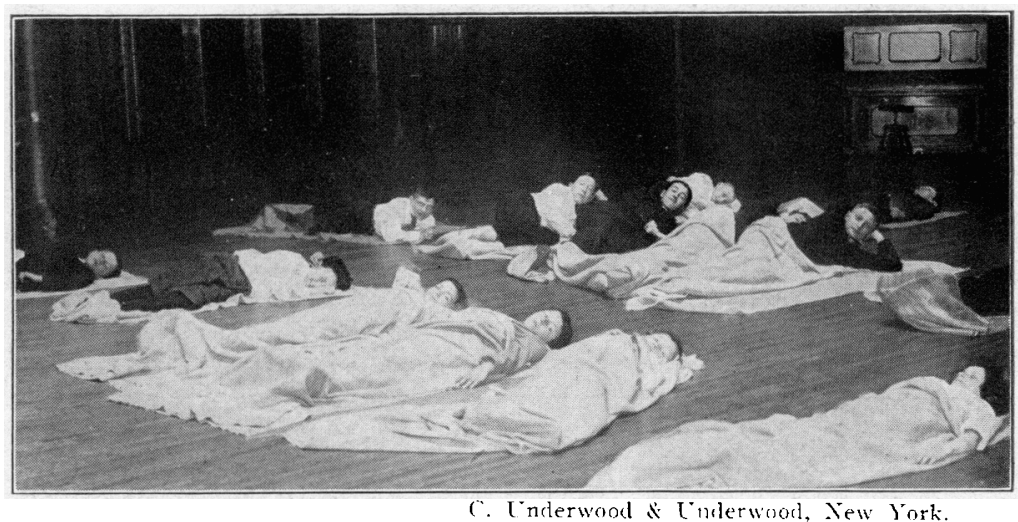

Fig. 2-Six of these children, five in the front row and the boy by the piano are taking their rest periods properly, lying flat on the back. The other six illustrate various improper positions. Many of these children fall asleep during the half-hour period of rest.

Specials.-Class Method; diet records; lunch; advised to take rest period.

Open-Air.-Instruction; diet records; rest; lunch.

An important olject in this varied treatment was to observe the value of direct feeding compared with that of instruction in health habits.

Results by the Class Mcthod.-The results for the four groups which had treatment by the Class Method are shown in Table 2.

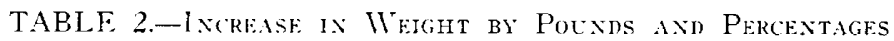

\begin{tabular}{|c|c|c|c|c|c|}
\hline Class & Gracle J & Grade VI & Gracle VII & Specials & 'lotal \\
\hline 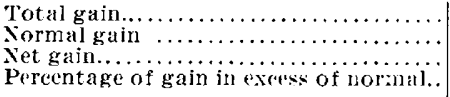 & $\begin{array}{l}55.7 \\
40.5 \\
15.2 \\
37.5\end{array}$ & $\begin{array}{r}109.0 \\
89.9 \\
18.1 \\
20.1\end{array}$ & $\begin{array}{r}72.0 \\
6.8 .8 \\
7.2 \\
11.1\end{array}$ & $\begin{array}{l}61.6 \\
43.2 \\
18.4 \\
42.6\end{array}$ & $\begin{array}{r}298.3 \\
238.4 \\
59.9 \\
25.0\end{array}$ \\
\hline
\end{tabular}


The total gain for the children in Grade $\mathrm{I}$ was 55.7 pounds. The expected" gain for the period during which the children were in the nutrition class (approximately nineteen weeks) was 40.5 pounds. The net gain made by the children was therefore 15.2 pounds. The percentage of gain in excess of normal is 37.5. The children in Grade VI for a similar length of time gained 109 pounds, which is 18.1 pounds more than the expected gain of 89.9 pounds for the period. The percentage of gain in excess of normal for Grade VI is 20.1. The children in Grade VII made a likewise satisfactory progress. Their total gain was 72 pounds as compared with an expected gain of 64.8. This leaves them with a net gain of 7.2 pounds, or a percentage of gain in excess of normal of 11.1. The total gain for the 17 "specials" was 61.6 pounds. Their expected gain was 43.2 pounds, giving a net gain of 18.4 pounds, or a percentage of gain in excess of normal of 42.6 . Thus these children gained almost 50 per cent. more than the average expected gain.

The result for all these children who had treatment by the Class Method is shown in the final column. Their gain was 298.3 pounds, while the expected gain was 238.4. This made an excess of 59.9 pounds, or a percentage of gain in excess of normal of 25 . In other words, these 94 children, to 62 of whom dinner was not provided, but all of whom were given instruction in health habits, and for some of whom certain physical defects were removed, gained 25 per cent. faster than was expected.

Results of Other Special Treatment.-Grade V, to whom dinner alone was provided, shows the poorest record. In this group twenty children were included in the beginning. At the end of the period fifteen of them were weighed the second time; the remaining five were not present for the second weighing. Their total gain for the period was 6 pounds. Their expected gain was 23.2 pounds. This means that the children of this grade to whom a sufficiently large midday meal was given, gained at only one quarter the normal rate. They were 74.1 per cent. behind what was expected of them.

3. The expected gain is calculated in the following way: The average yearly increase as given in the table of normal weights is used as a basis and a proportional increase for the period of the nutrition classes calculated. The normal increase for a 12 -year-old boy is 8 pounds. In the nineteen weeks he would be expected to gain approximately 3 pounds. A 15-year-old boy should gain 14 pounds in a year and in the nineteen weeks he would be expected to gain approximately 5 pounds. The expected gain thus refers to the normal or average increase for children of that particular age during the specified period. 
The children of the open-air class made a total gain of 13.7 pounds, whereas their normal gain would be 23.2. They thus gained at only about one half the rate expected of them. For this condition there is an explanation in the fact that instruction was given them, while all the other children in the open-air class were in the room. The Class Method of instruction and the spirit of cooperation and competition could not well be worked. There was a constantly disturbing element in the presence of children who did not need and were not interested in the nutrition work.

The foregoing statement presents a report for all the children for the whole period of approximately nineteen weeks.

Table 3.-Increase in Weight by Pounds and Percentages

\begin{tabular}{|c|c|c|}
\hline Class & Grade V & Open-Air \\
\hline 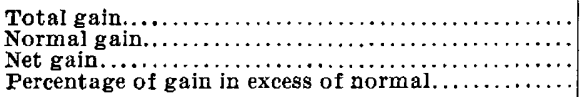 & $\begin{array}{r}6.0 \\
23.2 \\
-17.3 \\
-74.1\end{array}$ & $\begin{array}{r}13.7 \\
23.2 \\
-9.5 \\
-40.9\end{array}$ \\
\hline
\end{tabular}

In the first grade the children were only 6 years of age; the attendance of six of that age was unsatisfactory. In the sixth grade three boys were dismissed for misbehavior, three were transferred to the open-air class, and one joined the class very late in the season. In the seventh grade, also, two boys were dismissed for misbehavior. Of the specials, it was found impractical to retain two children who came in from another school; one girl was dismissed as a disorganizer, and one boy was registered but attended no class exercise. Toward the end of the school year, it was found necessary to transfer the classes from morning to afternoon because the room was needed for other purposes. Therefore, pupils had to be kept after school for nutrition work at a season of the year when they especially wished to be out of doors. Beginning in February and continuing throughout the nineteen weeks all children were weighed with indoor clothing; without shoes. It seemed impracticable to make allowances for the lighter clothing of May and June. However, slight changes in clothing represent an appreciable factor in dealing with percentages when the expected gain for the period is only 2 or 3 pounds. For these reasons, in addition to giving results for the whole group for the full period of nineteen weeks, the statement in Table 4 of the results of the first twelve weeks before changes in clothing were made, and when all classes were running smoothly, omitting the above mentioned nineteen children, gives perhaps a fairer view of results. 
The specials and Grade I made the most rapid relative gain. These groups were, however, of different ages, and their reactions should be compared to the older groups in only a general way. Grades VI and VII were of the same age, and their conditions of treatment varied only in one respect, namely, that Grade VI had the noonday dinner at the school, while Grade VII did not - yet their rate of gain is practically the same.

Table 4.-Increase in Weight by Pounds and Percentages*

\begin{tabular}{|c|c|c|c|c|c|}
\hline & $\begin{array}{l}\text { Grade I } \\
20 \text { Chil- } \\
\text { dren, Av. } \\
\text { Age } 6\end{array}$ & $\begin{array}{l}\text { Grade VI } \\
20 \text { Chil- } \\
\text { dren, Av. } \\
\text { Age } 12\end{array}$ & $\begin{array}{l}\text { Grade VII } \\
21 \text { Chil- } \\
\text { dren, Av. } \\
\text { Age } 12\end{array}$ & $\begin{array}{l}\text { Specials } \\
14 \text { Chil- } \\
\text { dren, Av. } \\
\text { Age } 10\end{array}$ & Total \\
\hline 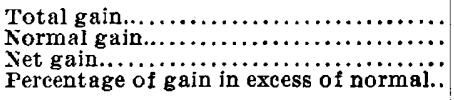 & $\begin{array}{r}47.6 \\
19.8 \\
27.8 \\
140.0\end{array}$ & $\begin{array}{l}51.4 \\
37.0 \\
20.4 \\
55.0\end{array}$ & $\begin{array}{l}58.1 \\
38.8 \\
19.3 \\
50.0\end{array}$ & $\begin{array}{r}54.2 \\
19.4 \\
34.8 \\
179.0\end{array}$ & $\begin{array}{r}217 \\
115 \\
102 \\
89\end{array}$ \\
\hline
\end{tabular}

* Compiled by the writer from same data as the other tables.

In view of the fact that nasopharyngeal obstruction is such an important factor in rate of gain, a further comparison may be made by eliminating from these two groups those who questionably needed operation. The eight remaining in Grade VI gained at the rate of 166 per cent., while the nine remaining in Grade VII gained at the rate of 154 per cent. above the expected rate of gain - further evidence that the midday dinner taken at the school had little or no effect on the rate of gain.

Factors Causing Malnutrition.-Physical Defects: An average of more than five defects in each child was found in this group of 125 children. Certain of these defects, as those interfering with respiration, may be considered causes for malnutrition, and certain others, as postural defects, may be considered results of malnutrition. However, these results may in turn become causes. The two most frequent defects found were nasopharyngeal obstruction and carious teeth.

Adenoids and Tonsils: The effects of nasopharyngeal obstruction: were apparent in 66 per cent. of these children. Whether nasopharyngeal obstruction continued to be a factor in the nutrition of the child could not be determined, but Chart 1 shows the relative gain, five weeks. before operation and five weeks after operation, of the nineteen children who received surgical treatment. These two five-week periods were separated by at least a week, so that the child's weight should be the same at the beginning of the second five weeks as it was at the end of the first five.

The question as to the need of operation in doubtful cases was answered in many instances by the failure of the child to gain, or, on 
the other hand, by his ability to make a good gain. In other words, the Class Method is a valuable clinical aid in the diagnosis of toxicity from inflammatory processes in the respiratory tract, whether due to obstruction or to septic infection.

Carious Teeth: Our results do not show a marked effect of carious teeth on the percentage of underweight. There were seventeen of our 105 children for whom no record was obtained, while of the remaining

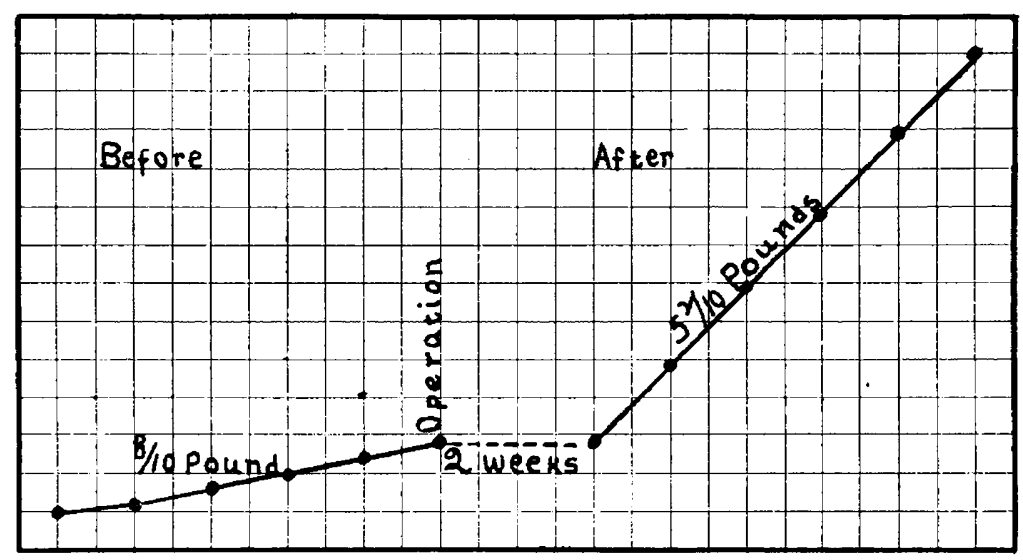

Fig. 3.-Adenoids and tonsils. Group of nineteen children showing average gain five weeks before and five weeks after tonsil and adenoid operation, allowing two weeks for recovery. P. S., 64, 1918.

eighty-eight children, twenty-five had no carious teeth; sixty-three, or 72 per cent., had from one to twelve carious teeth. The distribution of the children with the average percentage of underweight is shown in Table 5 .

TABLE 5.-Distribution of Underweight Children

\begin{tabular}{|c|c|c|c|c|c|c|c|c|c|c|c|c|c|c|}
\hline $\begin{array}{l}\text { No carious teeth....... } \\
\text { No. of children......... } \\
\text { Av. \% underweight...... }\end{array}$ & $\begin{array}{r}0 \\
25 \\
10\end{array}$ & $\begin{array}{r}1 \\
21 \\
9\end{array}$ & $\begin{array}{r}2 \\
12 \\
8\end{array}$ & $\begin{array}{r}3 \\
9 \\
13\end{array}$ & $\begin{array}{l}4 \\
8 \\
9\end{array}$ & $\begin{array}{r}5 \\
3 \\
10\end{array}$ & $\begin{array}{r}6 \\
\mathbf{3} \\
\mathbf{1 0}\end{array}$ & $\begin{array}{r}7 \\
2 \\
16\end{array}$ & $\begin{array}{r}8 \\
2 \\
10\end{array}$ & $\begin{array}{r}9 \\
1 \\
13\end{array}$ & $\begin{array}{r}10 \\
1 \\
9\end{array}$ & $\begin{array}{r}11 \\
0 \\
0\end{array}$ & $\begin{array}{r}12 \\
1 \\
13\end{array}$ & $\begin{array}{l}\text { No record } \\
\mathbf{1 7} \\
10\end{array}$ \\
\hline
\end{tabular}

It is to be noted that those children with five or six carious teeth were on the average 10 per cent. underweight, while one child who had twelve carious teeth was only 13 per cent. underweight. Twentyfive children had sound teeth; they were 10 per cent. underweight. Twenty-one children had one carious tooth; their average was 9 per cent. underweight. It is significant that the average per cent. underweight of these children with and without carious teeth remains approximately constant. 


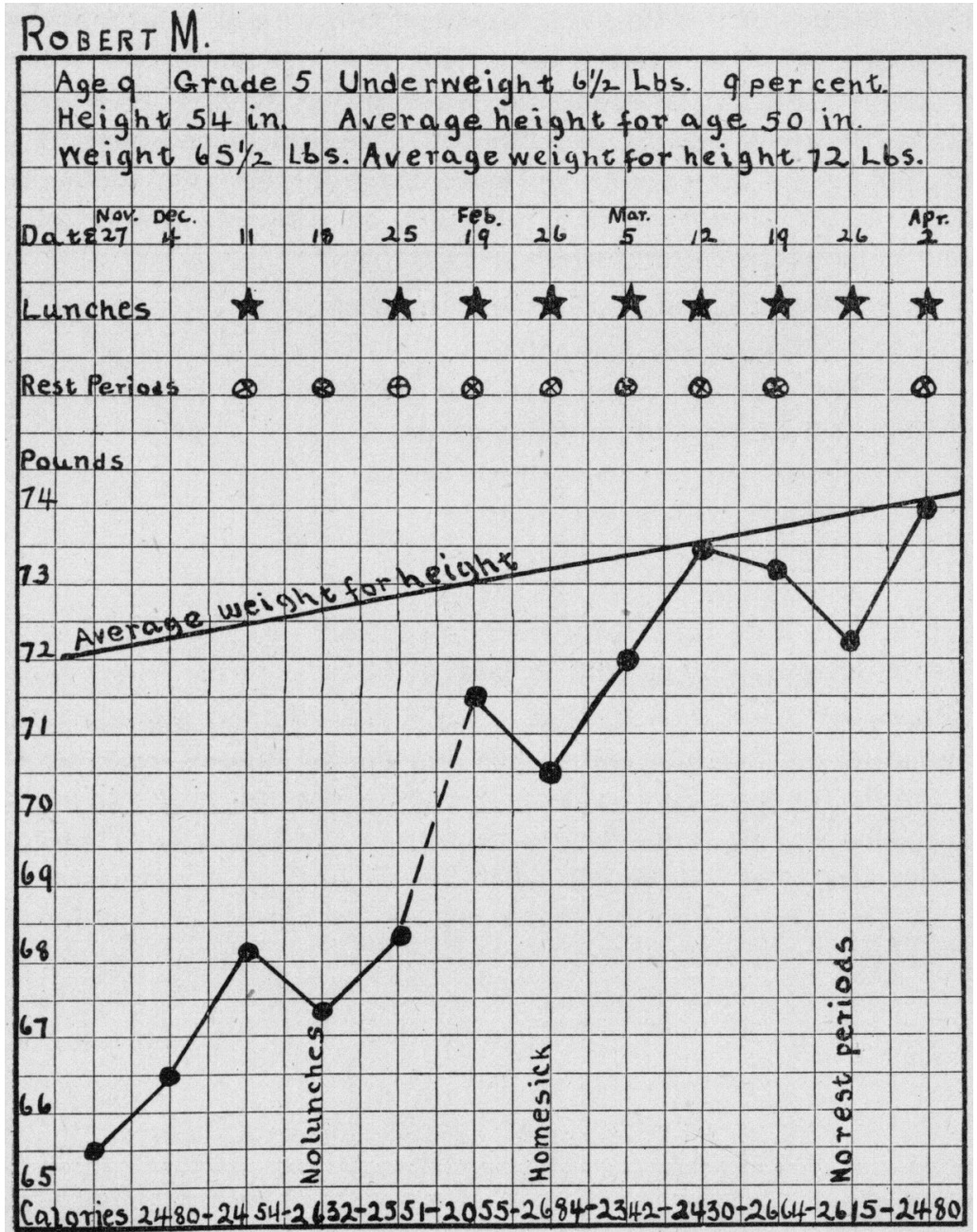

Fig. 4.-Specimen chart kept for each child under treatment by the class method. Red star represented by * means daily lunch; blue star represented by $\oplus$ means daily rest period; gold star, represented by $\bullet$ means greatest gain in week. The weight curve is that of a child, not in this group, chosen because he was under constant observation day and night together with eleven other children, all of whom lost weight on these same dates when lunches and rest periods were omitted the week preceding. On the original chart the weight curve is in red. Diagnosis of the cause of gain or loss in weight of children in the school group could be made by inference only, and therefore could not be verified. 
These observations agree with those reported in a previous article, ${ }^{4}$ where a group of 100 so-called well children showed 64 per cent. having carious teeth. However, excluding two with alveolar abscesses, twenty-two of these children who had severe malnutrition showed exactly the same percentage as the whole group, namely, 64 per cent. Both observations suggest that there may be faulty conditions of the teeth, but unless the carious processes affect the chewing surfaces or cause alveolar abscesses, there may not be sufficient production of toxins to interfere with nutrition.

Faulty Health Habits: The most frequent were:

1. The use of tea and coffee.

2. The omission of milk and cereals from the diet.

3. Fast eating and irregular meals.

4. The use of sweets between meals.

5. Sleeping with closed windows.

6. Overfatigue.

7. Late hours.

8. Too little time spent in the open air.

9. Irregular living due to lack of home control.

Power of the Class Method.-The Class Method appeals to the imagination of the child and makes him do for himself what no one else can do for him. It teaches and inspires him to "train for health" in the same way he trains to be a Scout or a good athlete. Therefore, ask him what you will, he will do it cheerfully if he is convinced it is good. The boy of 7 or 8 years steals off by himself, wraps himself in his blanket and takes his rest periods, or teaches himself to take and to like foods to which previously he had an aversion. He stops tea or coffee, goes to bed early, prepares his bed with hot water jug and papers between blankets, that he may sleep with his windows open on the coldest night. All this he does that he may get his star each week and see his weight go up. Two of these boys were heard to greet one another in the morning as follows: "How are you, Sam, this morning?" "Gaining, thank you." Another boy was told he could not be well and strong until his adenoids and tonsils were removed. He immediately secured permission for an operation from reluctant parents, went to the hospital alone and appeared in the school next day, feeling light headed and in some pain, but the operation had been performed. A parent who chanced to be a physician sent word to the clinic: "How do you get my boy and girl to do of their own accord the very things that I have not been able to get them to do, although I have tried for

4. Emerson, William R. P.: A Group Study of the Results of 100 Physical and Mental Examinations of So-Called Well Children, Internat. Clinics 2: Series 27. 
years." The children took their lunches and kept their rest periods holidays and Sundays. One boy planned his diet during Passover week in such a manner that he kept up his twenty-four-hour amount (calories) and continued to gain.

\section{CONCLUSIONS}

1. All children at the beginning of the school year should be weighed and measured, and once a month thereafter during the school year, that their condition and rate of growth may be known.

2. Parents and teachers of all children 7 per cent. or more underweight should be notified of their condition, that they may be given special observation and obvious causes for their malnutrition removed.

3. Malnourished children, especially, need a complete physical examination made in the presence of their parents, that the average of five or more physical defects, particularly those interfering with breathing, may be corrected and the children be made free to gain under proper hygienic conditions. Such complete examinations are welcomed by parents.

4. Malnutrition is not accurately diagnosed either by superficial school inspection or by the stethoscope.

5. Children 7 per cent. or more underweight should be grouped in open-air classes, school pressure removed, and the Class Method used in treatment as a part of the school program. The severest cases of malnutrition may be treated first, and so on until all cases are eliminated.

6. Rest periods in the midforenoon are necessary, especially where the school has one session. Rest should be taken lying down on the back with the windows open, blankets being provided for protection and warmth.

7. School lunches should be available. They should be served hot, and the serving should in itself be a practical means of education.

8. Provision of food is not in itself adequate to solve the problem of malnutrition.

9. Carious teeth do not necessarily cause malnutrition.

10. Each child should have his twenty-four-hour amount of food measured for two successive days each week, that his food habits may be known and if necessary corrected.

11. The Class Method of treating malnutrition is sound pedagogy. It is an effective method of teaching practical hygiene and the essentials of health. It represents an economy of time and energy for teacher, school nurse and administration. It is based on the principle of a "sound mind in a sound body," and that it is poor judgment to rate 
school efficiency on the amount of pressure that can be brought to bear on these already overburdened children in order that they may be made to graduate with their class and thus maintain a perfect school score.

12. There is no evidence in the weighing and measuring of these children that malnutrition, if left untreated, tends on the whole to correct itself. The percentage of malnutrition for the older children is no less than that for the young children. It is, then, fair to assume that the nation's list of physically unfit is supplied by this group of malnutrition children in the schools. Its percentage is about the same as has appeared in the Students' Army Training Corps and recruits for the army rated as physically unfit. The school system should not by its disregard of the physical condition of its children increase malnutrition. By weighing and measuring at regular intervals, by securing careful physical examinations, by teaching proper food habits and other essentials of health, it should graduate its children physically as well as mentally fit, thus eliminating malnutrition as an unnecessary element of national weakness. 